REVISTA DE ESTUDOS EM ARTES CÊNICAS

E-ISSN 2358.6958

\title{
Teatro e tecnologias de presença à distância: invenções, mutações e dinâmicas
}

\author{
Marta Isaacsson
}

\section{Para citar este artigo:}

ISAACSSON, Marta. Teatro e tecnologias de presença à distância: invenções, mutações e dinâmicas. Urdimento Revista de Estudos em Artes Cênicas, Florianópolis, v. 3, n. 42, dez. 2021.

do) DOI: http:/dx.doi.org/10.5965/1414573103422021e0117

Este artigo passou pelo Plagiarism Detection Software | iThenticate 
Teatro e tecnologias de presença à distância: invenções, mutações e dinâmicas

Marta Isaacsson ${ }^{1}$

\begin{abstract}
Resumo
O presente estudo aborda as criações teatrais performativas realizadas em tempo real no ambiente da rede internacional de computadores, problematizando as dinâmicas ali instauradas entre cena e recepção, atores/performers e espectadores. A partir do reconhecimento da natureza dos contratos entre o espectador e a cena promovidos pelas primeiras práticas teatrais associadas às teletecnologias, a reflexão discute as transformações aportadas pela tecnologia digital, destacando a importância de marcadores de visibilidade dos participantes entre si e das possibilidades de interação do espectador com a cena como fatores da instauração do sentimento de experiência coletiva na criação online em tempo real.
\end{abstract}

Palavras-chave: Performance Digital. Teatro virtual. Recepção.

Theatre and telepresence technologies: inventions, mutations and dynamics

\begin{abstract}
The present research addresses the performative theatre creations developed in real time in the environment of the international computer network, questioning the dynamics established between scene and reception, actors/performers and spectators. Based on the recognition of the nature of the contracts between the spectator and the scene promoted by the first theatrical practices associated with teletechnologies, the study discusses the transformations brought by digital technology, highlighting the importance of the participants' visibility markers among themselves and the possibilities of interaction of the audience with the scene as factors in the establishment of the feeling of collective experience in online creation in real time.
\end{abstract}

Keywords: Digital Performance. Virtual Theatre. Reception.

Profa. Dra. Programa de Pós-Graduação em Artes Cênicas e do Departamento de Arte Dramática da Universidade Federal do Rio Grande do Sul. Bolsista Produtividade de Pesquisa 1B/CNPq. Representante da área de Artes Cênicas no Comitê de Artes do CNPq 2019-2022. marta.isaacsson@gmail.com

(9) http://lattes.cnpq.br/0990182192329160 (iD https://orcid.org/0000-0002-1702-1030 
Teatro y tecnologías de presencia a distancia: inventos, mutaciones y dinámicas

\begin{abstract}
Resumen
El presente estudio aborda las creaciones teatrales de performance realizadas en tiempo real en el ambiente de la red internacional de computadoras, problematizando las dinámicas allí instauradas entre escena y recepción, actores/performers y espectadores. A partir del reconocimiento de la naturaleza de los contratos entre el espectador y la escena promovidos por las primeras prácticas teatrales asociadas a las tecnologías, la reflexión discute las transformaciones aportadas por la tecnología digital, destacando la importancia de marcadores de visibilidad de los participantes entre sí y de las posibilidades de interacción del espectador con la escena como factores de la instauración del sentimiento de experiencia colectiva en la creación online en tiempo real.
\end{abstract}

Palabras clave: Performance Digital. Teatro virtual. Expectación. 
Segundo registros na imprensa, há aproximadamente uma década, cientistas se preparavam para o surgimento de um vírus letal com potência de disseminação mundial, até então denominada de "doença X” (Craw, 2020; Thomas e Colin-Jones, 2021). Hoje, é cada vez mais difícil saber aquilo que é ou não verdade no mundo da informação. De toda forma, se os cientistas previam, os humanos comuns foram pegos desprevenidos pela pandemia da Covid-19, suas vidas transformadas em um quotidiano de incertezas, medo e dor diante de um cenário de mortes em número crescente diário desde o início de 2020.

A pandemia surpreendeu em uma primeira onda, prolonga-se em uma segunda, expande-se em uma terceira, com novas cepas do vírus e, depois de um ano, carregando mais de um milhão de vidas, obriga a humanidade ao reconhecimento diário da impermanência de sua existência. Atos de barreira ao contato com o outro e o mundo se afirmam como atos de sobrevivência, ainda que muitos, na sua onipotência, não os respeitem. A exigência de distanciamento social para contenção do vírus compromete o convívio presencial por meio do qual normalmente selamos pactos de cumplicidade e afeto. E, naturalmente, compromete a realização do teatro e das demais artes do espetáculo, em suas formas tradicionais de encontro humano.

Para o mundo do Teatro, da Dança e da Performance, o distanciamento social, iniciado em março de 2020 e sem data de término, colocou-se, em um primeiro momento, como uma tragédia. A copresença de artistas, técnicos e espectadores em um mesmo espaço-tempo constitui condição pré-expressiva das artes da cena. Assim, enquanto a humanidade, assustada com a pandemia, se interroga sobre seu próprio destino, os artistas de teatro se interrogam também sobre o destino de sua arte. Para o mundo do teatro, a vida parece ter "pregado uma peça", e uma cascata de perguntas se forma, à semelhança daquela do poema José, de Carlos Drummond de Andrade (2012, p.32). E agora, Teatro? O espetáculo acabou, a luz apagou, o povo sumiu... E agora, teatro?²

No contexto das limitações impostas pela pandemia da Covid-19, a humanidade vem encontrando inúmeras saídas no emprego das tecnologias 
digitais. A internet assumiu um papel capital para todos aqueles que têm a chance de ficar em confinamento, e assim escolheram, para salvar não só suas vidas, mas também aquelas dos mais vulneráveis. É graças a essas tecnologias que estão sendo mantidos elos familiares, sociais e de trabalho, além do agenciamento das necessidades básicas de sobrevivência. Toda desconfiança acerca da rede internacional de computadores, do controle subterrâneo de suas plataformas sobre nossas vidas, como revela o documentário O Dilema das Redes Sociais, precisou ser relativizada, pois Deus ex machina, com muitos bits, plataformas e redes sociais, colocou-se como a única possibilidade de salvar uma parte de nós.

Se a arte é o campo do sensível, sua história é a da resiliência dos artistas. Assim, tal qual José de Drummond, tal "qual um bicho do mato", o teatro resiste e abre portas no ciberespaço para preservar sua existência social e nutrir de matéria sensível a sociedade assustada pela peste do século XXI. Neste movimento teatral de sobrevivência, diferentes ações tiveram lugar por meio da rede de computadores.

Em reação às restrições de convívio social, importantes coletivos artísticos do mundo inteiro, como o Teatro Oficina, a companhia inglesa Complicité, o francês Théâtre du Soleil e o americano Wooster Group, passaram imediatamente a apresentar, em datas e horários definidos, documentos em vídeo de espetáculos importantes de seus repertórios, muitos dos quais já disponíveis à comercialização, em formato DVD. Foi realmente uma grande oportunidade assistir ou reassistir a essas produções. No Brasil, o Itaú Cultural se somou ao esforço dos grupos e implementou o projeto Palco Virtual, com uma programação diversificada de difusão de registros audiovisuais de espetáculos, contemplando produções teatrais de diferentes estados da nossa federação e de interesse de adultos e de jovens.

Com o prolongamento da exigência de distanciamento social, uma segunda iniciativa se fez ainda no primeiro semestre de 2020: apresentações online em tempo real de adaptações de espetáculos teatrais, originalmente concebidos para o palco e apresentados em teatros antes da pandemia. No âmbito do programa EmCasaComSesc, promovido pelo setor cultural paulista do SESC, monólogos ganharam o ambiente virtual, em interpretações preciosas de atores expoentes do 
cenário artístico do país, como Renato Borghi, Celso Frateschi, Sérgio Mamberti e Matheus Nachtergaele. Em tempo real, a performance on-line se aproxima em parte da experiência vivenciada pelos atores e pelos espectadores no teatro basilar. A partilha do tempo aporta à performance a vulnerabilidade a imprevistos - própria da realidade no tempo presente -, aos quais se somam no on-line a possibilidade de interrupção da conexão da rede. O contexto de distanciamento social exige do ator desdobramentos ímpares. Absolutamente só, diante de uma iluminação e de uma câmera, ele se torna o autor único da imagem audiovisual. Em recente depoimento, no âmbito de uma homenagem do Conselho de Cultura do RS, Matheus Nachtergaele explicava ter preferido não repetir a realização em livestream do espetáculo Desconscerto, embora tenha sido uma experiência interessante, em razão do difícil desafio de atuar para ninguém, lembrando que na produção em cinema e televisão há sempre um outro, pelo menos o diretor de fotografia. A colocação de Nachtergaele faz pensar sobre a importância da presença da testemunha na arte do ator e o quão difíceis são os processos por ora desenvolvidos.

O confinamento prolongado e editais públicos de socorro a artistas e grupos impulsionaram a produção de espetáculos especialmente concebidos para apresentações no modo livestream, explorando a potencialidade das ferramentas das plataformas de videoconferência. Sob o tema Corpo do Futuro: Humanidade e Natureza, o consagrado festival Porto Alegre em Cena pautou a edição do 15o Prêmio Braskem, convocando os artistas locais à criação (ou adaptação) de trabalhos para apresentações on-line em tempo real, por meio de plataformas e formatos os mais diversos. O vencedor Carcaça, criação de João Gabriel OM e João Pedro Madureira, investe na potência da palavra e na construção de uma visualidade multimídia, resultante da sobreposição dos gestos, dos movimentos e das falas do performer com imagens e vídeos como tela de fundo. Apresentada pela plataforma Zoom, a criação tinha apoio técnico de dois computadores, um destinado à captura da atuação do performer e o outro, ao gerenciamento das imagens pré-gravadas.

Dentro das criações brasileiras produzidas especificamente para difusão em livestream, ganha destaque o espetáculo A Arte de Encarar o Medo, do coletivo 
paulista Satyros, um projeto internacional, produzido em três versões com elencos distintos (brasileiro, norte-americano e afro-europeu), que teve grande repercussão, reunindo público de inúmeros países, falantes de 20 línguas. É preciso lembrar que o interesse de Satyros pelas ferramentas digitais não começa na pandemia. Em Hipóteses para o Amor e a Verdade (2009), o público era convidado a manter seus celulares ligados e a informar os números à equipe, de forma a permitir que, no curso do espetáculo, comunicações entre atores e espectadores se fizessem por meio de mensagem de texto. Em 2014, ano de comemoração dos 25 anos do grupo, Satyros realizou o projeto $E$ se fez a humanidade ciborgue em 7 dias, reunindo sete criações sobre o tema da relação do homem com a tecnologia, nas quais maquinarias e dispositivos digitais eram elementos cênicos determinantes e eram realizadas comunicações inclusive com a deep web. A criação $A$ Arte de Encarar o Medo traz para o centro da ação dramática a própria pandemia. As personagens encontram-se em 2035 e, confinados há 15 anos, buscam formas de sobreviver ao medo. Assim, o contexto dramático das personagens e a realidade dos espectadores se mesclam. A plataforma Zoom se coloca tanto como meio de difusão da performance ao espectador quanto como ferramenta de comunicação das personagens. O eixo dramático, a contracenação direta entre personagens, concretiza-se pelo olhar dos atores voltado para a câmera, promovendo uma ambiguidade de destinatários do enunciado, já que a câmera é, ao mesmo tempo, o ator parceiro e o espectador. Opera-se ali uma ruptura da "tela", à semelhança da ruptura da quarta parede do palco, contribuindo para uma imersão do espectador no universo da representação. No palco virtual, a entrada e a saída de cena se efetuam na abertura e no fechamento das janelas de comunicação; seguidamente, o foco cênico se multiplica, construindo um mosaico pós-dramático, e se reduz no abrir e fechar das janelas; os enquadramentos dos atores em primeiríssimo plano tornam a expressão do rosto e a palavra dita elementos capitais da atuação cênica. Entre atuações realistas ou não, a exploração de efeitos visuais oferecidos pelas ferramentas da plataforma e a integração de imagens externas garantem uma teatralidade particular.

Esse último grupo de criações, concebidas e realizadas graças à exploração 
do potencial multimídia oferecido pelas ferramentas das plataformas de videoconferência, ganha interesse da crítica e, ao mesmo tempo, suscita debates entre artistas e estudiosos. Neste contexto de discussão, parece importante colocar as propostas atuais na rede de computadores dentro de eixo histórico de experiências teatrais anteriores de presença à distância e dentro do qual se pode reconhecer as mutações de dinâmicas envolvidas na relação cena e recepção.

Para muitos, a articulação do teatro à rede de computadores parece ser um fato novo. É bem verdade que o teatro teve uma aproximação comedida com a rede global de computadores quando comparada àquela de outros domínios artísticos, inclusive da dança, modalidade artística que integrou rapidamente a tecnologia digital em seus processos de criação, constituindo notadamente o que veio a se denominar de Dança Telemática, questão que motiva as relevantes pesquisas empíricas desenvolvidas pela pesquisadora brasileira Ivani Santana ${ }^{3}$. Soube também a dança investir em ambientes interativos, nos quais os movimentos dos bailarinos, por meio de sensores, são traduzidos em tempo real em som, música ou projeções de vídeo.

Entre as muitas razões possíveis para ter sido contido e lento o movimento de aproximação do teatro com as ferramentas digitais, pode-se referir a cultura teatral essencialista, na qual a afirmação da identidade do teatro esteve muito arraigada a sua diferenciação da produção audiovisual tecnológica. Embora, desde o tempo da Grécia Clássica, o teatro tenha se beneficiado de invenções técnicas e, no início do século XX, realizado, inclusive, profícuas trocas técnico-estéticas com o cinema, o movimento de contracultura e a releitura dos textos de Artaud, nos anos 60, promoveram no mundo do teatro o desenvolvimento de um pensar essencialista muito forte, dentro do qual o convívio carnal entre ator/espectador se sobressaía como essência e mesmo como o todo do acontecimento teatral. Ilustra o espírito dessa época, cuja potência reverbera até hoje, a sustentação de Grotowski (1976, p.5) de que o único elemento sem o qual o teatro não pode existir é a relação ator-espectador, em comunhão direta e viva.

3 Líder do grupo de pesquisa Poéticas Tecnológicas, cujas produções encontram descritas no site da pesquisadora. Disponível em: http://poeticastecnologicas.com.br/ivanisantana/bio-e-curriculum/. Acesso em: 26 abr. 2021. 
A primazia do encontro carnal entre artista e espectador faz do corpo do ator/performer o elemento central da criação teatral, motivando, nas últimas décadas do século XX, a emergência de múltiplas pesquisas centradas no treinamento e nas práticas corporais do ator-performer, tais como aquelas desenvolvidas por E. Barba. Nesse contexto, tudo que se referia à "tela", aos mundos do audiovisual e da informática, soava com antítese do teatro. Até mesmo o registro de um espetáculo, para fins de arquivo, foi por muito tempo visto com grandes reservas. Desde o seminário internacional "Filmar o Teatro", organizado em Paris em 1977 por Denis Bablet, foram inúmeras e acirradas as discussões acerca da legitimidade de registros cine/videográficos de espetáculos teatrais, envolvendo artistas e críticos. Isso porque, para muitos criadores e estudiosos, filmar significava trair o teatro.

Mas o tempo movimenta os pensamentos, e hoje a produção de registros audiovisuais dos espetáculos se tornou fato usual. E, por ocasião do fechamento dos teatros, em decorrência da pandemia da Covid-19, foram justamente os registros em vídeo de espetáculos que saíram dos arquivos dos coletivos teatrais de todas as partes do mundo. Foi no material audiovisual que muitos grupos encontraram, no primeiro momento do distanciamento social, uma forma de manter a partilha sensível com seus públicos.

No conjunto das iniciativas postas na rede, em resposta às exigências de distanciamento social, despertam maior discussão aquelas concebidas como arte específica para o ambiente virtual da rede de computadores, na medida em que problematizam as noções tradicionais de espaço e tempo e, por consequência, de presença. De forma a evitar ingenuidades históricas, parece importante trazer aqui referências artísticas que dão conta de que, a despeito da resistência filosófica, já faz aproximadamente trinta anos que artistas de teatro europeus e americanos começaram a explorar em suas criações os espaços de encontro da rede de comunicação, por meio de MUD, MOO, salas de chat, ambientes VRML e, mais recentemente, a second Life. A atual explosão de iniciativas na rede de computadores, em decorrência das restrições de contato físico, vem, na realidade, dar visibilidade a um movimento de experimentações, concebidas como teatrais, no ambiente da rede de computadores, cujo começo se deu no início dos anos de 
1990. É bem verdade que esse movimento demorou muito a ser percebido pela crítica especializada. Na primeira versão (1999) de seu renomado livro Teatro Pósdramático, Hans-Thies Lehman, por exemplo, não problematiza ainda o emprego da internet pelo teatro, vindo a fazê-lo posteriormente, como pode ser constatado na versão da obra traduzida no Brasil.

Concebidas como obras teatrais pelos artistas envolvidos, as primeiras experiências se fizeram por meio de salas de chat, plataformas de reuniões, aplicativos de mensagens. Entre essas iniciativas pioneiras, destaca-se a produção Hamnet (1993), uma paródia de Hamlet, concebida pelo ator inglês Stuart Harris, residente à época na Califórnia, e realizada pelo aplicativo Internet Relay Chat (IRC) por meio do qual era possível ter um espaço de reunião em canal privativo e realizar a comunicação por meio de mensagem de texto em tempo real. Essa primeira experiência impulsionou a constituição do coletivo artístico Hamnet Players ${ }^{4}$, que prosseguiu com novas criações no IRC, entre as quais PCbeth: an clone IBM Clone of Macbeth (1994) e An IRC Channel Named \#desire (1995), inspiradas, respectivamente, nas famosas tramas de Shakespeare e Tennessee Williams.

O caráter teatral dessas experiências era assim compreendido por seus criadores em função de um conjunto de aspectos. Inicialmente, as apresentações dessas criações "teatrais" na rede de computadores ocorriam em data e horário previamente definidos, na presença concomitante de atores e espectadores em sala virtual específica, todos os participantes identificados por meio de pseudônimo, independentemente de atuarem ou simplesmente assistirem à ação dos outros. A sala virtual torna-se, então, espaço de convívio, à semelhança da situação vivenciada no espaço físico real do teatro; é nela que a ação dos atores se dá e é nela que os espectadores assistem à atuação dos atores. Para Harris (1999, p.500):

uma vez que todos os participantes de uma conversa de IRC podem escolher qualquer apelido pelo qual desejam ser conhecidos e uma vez que um canal de IRC pode reunir muitas pessoas que não atuam, mas apenas assistem, os elementos do teatro estão ali: um elenco de personagens com nomes como Hamlet, Ofélia, Polonio etc. pode ser

${ }^{4}$ Disponível em: https://www.marmot.org.uk/hamnet/. Acesso em: 14 fev. 2021. 
reunido e um público convidado a assistir ${ }^{5}$

Para os criadores de Hamnet, a experiência guardava um caráter teatral, pois a rede de computadores não estava sendo usada para transmitir um espetáculo, mas para realizar improvisações em tempo real, por meio de mensagens textuais, a partir de roteiro de base inspirado na trama da obra de Shakespeare e em presença virtual de espectadores. A produção da escrita constitui, assim, o próprio espetáculo. Nessa situação, os atores encontravam-se tão vulneráveis a acidentes e a intervenções indesejadas quanto nas circunstâncias tradicionais de convívio no teatro.

A experiência de Hamnet Players motivou novas iniciativas "teatrais" no âmbito da net. Antoinette LaFarge, colaboradora de Hamnet Players, juntou-se a outros artistas para fundar o Plaintext Players ${ }^{6}$, coletivo artístico que, durante seis anos, se dedicou à improvisação online em tempo real'. Com a performance Christmas (1994), o Plaintext Players deu início à realização de nove performances, empregando aplicativos de salas de chat. Embora o sistema de programação empregado fosse similar àquele da versão online de jogos de Role Playing Game (RPG), a plataforma das criações do Plaintext Players se organizava de forma distinta. Os elementos ficcionais eram mínimos e as regras flexíveis, fatores que contribuíam tanto para maior liberdade dos participantes quanto para a definição de papéis, dos objetivos e, também, para o desenvolvimento das improvisações. Os participantes tinham, assim, poder efetivo de intervenção.

Ainda que concretizadas exclusivamente por meio de comunicação escrita, Lafarge (1995) sustentava também o caráter teatral das criações realizadas no ambiente virtual, sob o argumento de que essas criações seguiam o mesmo modelo operatório do teatro, ou seja, a identidade dos protagonistas e a trama eram apresentadas, pouco a pouco, no desenrolar de um diálogo, pela troca entre

\footnotetext{
...since all participants in an irc conversation may choose whatever nickname they wish to be known by...and since an irc channel may contain many people who contribute nothing, but merely watch, the elements of theatre are there: a cast of characters with names like Hamlet, Ophelia, Polonius etc. can be convened and an audience invited to watch. (Tradução nossa)

${ }^{6}$ Disponível em: http://yin.arts.uci.edu/ players/index.html. Acesso em: 17 fev. 2021.

Sob a direção de Robert Allen, o grupo passou nos últimos anos a se consagrar a criações de telemática, fazendo-se presente em importantes festivais europeus.
} 
os personagens. A teatralidade aparece aqui associada à carpintaria do drama e não à especificidade do acontecimento teatral. Em sua argumentação acerca da teatralidade de suas experiências, LaFarge aproxima ainda a prática dos atores internautas com aquela dos atores da Commedia dell' arte, destacando que, no ambiente virtual, os atores improvisam sobre a base de um personagem preestabelecido e de um roteiro, eles mesclam falas de sustentação da trama com falas improvisadas, fruto do jogo interno da cena, e também exploram fatos da atualidade. É interessante pensar que o jogo dramático esvaziado da cena pósmoderna, no qual as ações performativas ganham evidência, reaparece de alguma forma recriado no ciberespaço.

O desenvolvimento tecnológico deu surgimento ao chat visual em 1994, permitindo possibilidades novas para além da interação textual. Em 1995, surgiu a plataforma Athemoo, desenvolvida pela University of Hawaii em parceria com a instituição americana Association for Theatre in Higher Education (ATHE), com o objetivo de permitir a participação do maior número possível de artistas e técnicos de teatro em reuniões de interesses profissional, sem que eles tivessem que se deslocar, já que a classe artística enfrentava à época grandes dificuldades financeiras. Não demorou muito, porém, para que a plataforma, estruturada como sala de chat, passasse a ser explorada também para a criação artística e a realização de performances interativas por meio de trocas textuais.

Foi na plataforma Athemoo que teve origem o hiperdrama, com a criação, em 1996, de Bride of Edgefield, de Charles Deemer, escritor e dramaturgo americano. Tratava-se de um roteiro sob a forma de hipertexto, ou seja, articulando variados elementos, palavras, sons, imagens, organizado em torno de cenas que transcorriam simultaneamente. Segundo Deemer, o hiperdrama se distinguia do teatro tradicional por oferecer ao espectador internauta a possibilidade de definir o fluxo da ação, já que tinha autonomia de escolha sobre o percurso de cenas a assistir. De forma distinta ao processo vivenciado no teatro tradicional, no qual o encadeamento se encontra previamente organizado, o espectador-usuário, investido de uma posição de voyeur, era convidado a construir a trama e, nesse sentido, explica Deemer, muitas vezes ele retorna para rever cenas. A interação natural do teatro, a troca de energia do face a face se via, então, substituída pela 
interatividade, ou seja, uma participação na rede.

Na esteira de Hamnet Players e de Plaintext Players, Adriene Jenik e Lisa Brenner fundaram o Desktop Theatre, anunciando um novo tipo de teatro de rua, o Internet Street Theater. Esse teatro de rua digital se fez, inicialmente, graças ao aplicativo gratuito The Palace, de simples utilização e conexão por meio de linha telefônica. As características gráficas do aplicativo possibilitavam a composição de cenários, ilustrações produzidas em tempo real, além da participação de cada usuário por meio de avatares, visualmente personalizados, e que ganhavam voz por meio de áudio produzido pela transcrição dos textos digitados graças a plugin específico. Representados por meios de pequenos avatares, todos os usuários, atores ou espectadores encontravam-se, assim, em um mesmo espaço e permaneciam "presentes" para todos, independentemente de atuação ou reação.

A primeira plataforma concebida especialmente para realização de performances online, da qual se tem registro, foi desenvolvida pelo Avatar Body Collision, coletivo fundado por iniciativa da neozelandesa Helen Jamieson, antiga colaboradora do Desktop Theatre, em parceria com Vicki Smith (Nova Zelândia), Karla Ptaček (Royaume-Uni), Leena Saarinen (Finlândia). Após a realização de criações por meio das plataformas The Palace e I Visite, Avatar Body Collision promoveu o desenvolvimento de UPStage (2004), aplicativo gratuito de código aberto, que reúne possibilidades de uso de textos, gráficos, áudios, webcams, animação e desenho ao vivo. Graças à multiplicidade de ferramentas, Upstage se tornou um espaço de interação intermedial, onde a presença e as ações dos performers e dos espectadores se fazem por meios diversos. Em suas improvisações, os participantes podem usar a escrita, o áudio por meio do dispositivo text2sppech, colagens de imagens pré-gravadas, trechos de filmes, elementos gráficos, sons e outros recursos. A plataforma Upstage possibilitou a realização de inúmeras performances e, entre 2007 e 2014, sediou festivais de performances online. Desde sua primeira versão, a plataforma passou por atualizações e, em setembro 2021, o último upgrade deverá estar concluído.

Nas mais diversas estéticas, a existência do teatro pressupõe a copresença em mesmo espaço-tempo de atores, técnicos e espectadores. É justamente essa copresença que pontua a distinção essencial entre teatro e cinema, traçada por 
Walter Benjamin no famoso estudo A obra de arte na era de sua reprodutibilidade técnica, de 1935. É também essa copresença, então destacada pelo pesquisador argentino Jorge Dubatti (2007) como “convívio”, que define a ontologia do teatro.

Em todas as criações cênicas em ambientes exclusivamente digitais, desde as primeiras realizadas em chats de texto até as atuais, em plataformas de videoconferência, não há, evidentemente, a copresença em mesmo espaço físico entre performers e espectadores e, no contexto das exigências de distanciamento social, não há nem mesmo entre performers. Assim, não parece fértil discutir as práticas teatrais remotas adotando-se como parâmetro de análise o teatro basilar, cuja dinâmica está instaurada a partir da unidade espaço-temporal de atores e espectadores. Parece mais promissor interrogar o teatro e a performance digitais naquilo que aportam em termos de transformação à percepção do espectador, dentro do campo das criações associadas às tecnologias de presença à distância. Para tanto, é preciso, inicialmente, reconhecer que a presença à distância não é um fato técnico novo e que há muito o teatro faz uso de invenções capazes de expandir sua atuação. Antes da tecnologia digital, o desenvolvimento da telefonia, do rádio e da imagem eletrônica motivou o surgimento de novas formas de tornar presente o teatro no seio da sociedade, para além do acontecimento teatral.

O cruzamento do teatro com as teletecnologias de comunicação à distância tem início na criação do teatrofone, apresentada por Clément Ader, na Exposição Internacional da Eletricidade de Paris em 1881, criação que, alguns anos depois (1889) daria origem na França à Companhia do Teatrofone. Reunindo um conjunto de teatros associados, a companhia oferecia, por meio de uma assinatura mensal, a transmissão em tempo real de espetáculos de teatro ou de ópera pelo telefone; essa iniciativa logo se estendeu por toda a Europa e durou até meados dos anos de 1930. No andamento histórico, após o teatrofone, vieram o radioteatro e o teleteatro (ou teatro televisado), que no Brasil tem sua memória no Grande Teatro da Tupi. A despeito de suas diferenças, todas essas formas de teatro constituem "telecenas", termo cunhado por Clarisse Bardiot em sua tese Les Théâtres Virtuels (2005). Trata-se de experiências artísticas realizadas à distância, como bem define o prefixo grego “têle”, por meio de dispositivo tecnológico. É dentro dessa linhagem de telecenas que as criações contemporâneas em ambiente virtual parecem 
melhor se colocar ao estudo.

Se podemos discutir o enquadramento ou não do teatro basilar nas teorias dos meios, as práticas cênicas combinadas às tecnologias de comunicação à distância não escapam a esse campo teórico. Estando os artistas e os espectadores mediados, toda análise do potencial estético das telecenas passa pelo reconhecimento das especificidades da mediação envolvida. É nesse sentido que interessa retornar ao pensamento de McLuhan (1969), notadamente a tese de que cada meio promove efeitos específicos na percepção humana.

O vinculo genético de cada modalidade de telecenas com determinado meio de produzir presença à distância convida a pensar as telecenas na perspectiva dos fenômenos perceptivos envolvidos, sobre as mudanças dos efeitos sobre a percepção do espectador de uma modalidade em relação a outra, decorrentes da natureza do meio e do modo de exploração da tecnologia de presença à distância.

Da cena do teatrofone às realizações em ambiente digital, passando pela imagem eletrônica, transformações importantes na qualidade da experiência perceptiva da expectação podem ser observadas. O teatrofone não promoveu o surgimento de uma forma específica de teatro, uma vez que se tratava de uma retransmissão de espetáculos realizados dentro de contextos teatrais convencionais. Entretanto, essa retransmissão pelo telefone representou uma mudança significativa na vivência do espectador em relação àquela experienciada nas condições tradicionais do teatro. Entre as muitas mudanças, é importante destacar a passagem da vivência coletiva à particular e a alteração da posição do espectador em relação à cena, pois ele deixou de estar em frente aos atores para se encontrar virtualmente no meio deles, graças aos dispositivos de captação de som instalados no interior do palco. Essas duas alterações promovidas pelo teatrofone contribuíam para a imersão sensorial do espectador na cena, ainda que de forma precária, em razão dos próprios recursos técnicos disponíveis à época.

Embora a escuta do radioteatro se fizesse em âmbito particular, ela deixava de ser solitária como no teatrofone, pois a escuta de peças radiofônicas se realizava, frequentemente, em reunião de familiares ou amigos. Dessa forma, o radioteatro possibilitava, ainda que de forma limitada, uma vivência partilhada 
entre espectadores, atualizando em certa medida aquela do acontecimento teatral. Ao lembrar a importância do rádio para a existência política de Hitler e o impacto da emissão radiofônica de Orson Welles sobre a invasão dos marcianos, McLuhan (1969, p. 337) destaca o poder da imagem auditiva do rádio em afetar as pessoas; para ele, o rádio é mesmo capaz de transformar a "psique e a sociedade em uma única câmara de eco”. Essa forte potência do rádio se deve, segundo McLuhan (1969, p. 301), à "alta definição" da imagem sonora do rádio, diferente daquela do telefone, que desperta os sentidos e faz com que "visualizamos a experiência ou a completamos com o sentido de visão". O espaço aberto à imaginação e o convite à completude da imagem sonora promovem no espectador um vínculo íntimo com a cena, ela é também sua e, consequentemente, instauram-se as condições de uma imersão ficcional à semelhança daquela da leitura do livro.

Assim como o radioteatro, o teleteatro vem oferecer a possibilidade de uma experiência coletiva em particular. Graças ao desenvolvimento da imagem eletrônica, a cena passa a ser "vista" e, consequentemente, o espectador deixa de estar no interior da cena, como proporcionava o rádio, e a separação entre palco e plateia encontra-se restaurada. A imagem visual do teleteatro diminui naturalmente o espaço de imaginação do espectador, mas tal redução é compensada por uma cena cada vez mais qualificada, realista e ilusória.

O convívio entre atores/performers e os espectadores envolve, em primeira instância, o reconhecimento de cada um da presença de todos os outros. No contexto das primeiras telecenas (teatrofone, radioteatro e teleteatro), o espectador não está visível aos atores nem aos demais espectadores. Mas as tecnologias digitais aportaram ferramentas capazes de transformar essa dinâmica. Enquanto a malha de conexões da rede desfaz as fronteiras geográficas e oferece a possibilidade de reunirem-se espectadores de todas as partes do planeta, as plataformas, os aplicativos e as câmeras permitem criações artísticas que oportunizam aos espectadores marcarem sua presença por distintos recursos (cifras, codinomes, avatares, intervenção de voz e mesmo de imagem), tornandoos visíveis para todos e, com maior ou menor frequência, autorizando-os a se manifestar. Enquanto o rádio significou, segundo McLuhan, um avanço em relação 
ao telefone, por permitir a passagem da escuta individual à coletiva, as tecnologias digitais ofereceram outro avanço, ao possibilitar o reconhecimento, ao espectador, da presença dos demais e, assim, a constituição de um público, enquanto coletividade que se reconhece e partilha uma mesma experiência.

A visibilidade do espectador nas performances digitais aparece em graus distintos, conforme as formas e as ferramentas de participação autorizadas pela própria obra. Nesse sentido, a presença do espectador vai desde a presença discreta, sem atuação efetiva sobre o desenvolvimento da performance, à presença participativa, que intervém na composição da obra, passando pela presença intermitente, quando o espectador é convocado a se expressar esporadicamente. Marca a abertura do espetáculo Carcaça, por exemplo, o pedido do performer aos espectadores para que apaguem suas câmeras e escureçam os ambientes onde se encontram, em nítida busca de aproximação da experiência que se inicia com aquela vivenciada do contexto teatral tradicional. Na sequência, em momentos pontuais, o espectador é convidado a responder, pelo chat ou diretamente em áudio, a perguntas feitas pelo performer, restaurando em certa medida o caráter de experiência compartilhada, próprio do acontecimento teatral.

É de se considerar que os variados modos de participação do público suscitem modulações distintas da experiência coletiva tanto no espectador quanto no ator. Assim como a experiência do espectador, aquela dos atores do teatro digital se encontra remodelada em relação às modalidades de telecenas precedentes, em razão da visibilidade dos espectadores. Atuar para um público invisível, como o caso do radioteatro e do teleteatro, é diferente de atuar reconhecendo a presença dos espectadores e, mais ainda, quando thes é dada a possibilidade de se manifestar ou agir durante a performance, por meio de variados marcadores e conforme a estrutura da obra.

Independentemente da forma pela qual atores e espectadores marcam suas presenças no ambiente virtual, essas presenças são espectrais e suas identidades não revelam um lugar de existência. Todos são viajantes de um não lugar, transeuntes de um espaço fluido e sem contornos, onde não existe separação entre cena e plateia. Atores e espectadores encontram-se em um mesmo terreno e, à semelhança de um teatro "participativo", são as modalidades de suas ações, 
possibilitadas dentro de uma gama de ferramentas, que desenham um traçado invisível separando o universo de uns e de outros.

Com a publicação de Remediation: Understanding New Media (1999), Jay Bolter e Richard Grusin introduziram no campo da teoria dos meios uma tese importante, a da remediação dos meios, cuja ideia central é a de que o surgimento de um novo meio envolve um fenômeno de remediação ou remodelagem de meios precedentes, como é o caso da fotografia, do filme e da televisão. Esse fenômeno opera, segundo os pesquisadores, dentro de duas lógicas opostas, mas gêmeas: a imediação, cujo princípio é a transparência do meio, seu aparente desaparecimento, em prol da percepção de contato direto com o conteúdo, e a hipermediação, cujo princípio é a opacidade do meio, a visibilidade da interface.

O vínculo genético das telecenas com os meios permite pensar essas duas tendências no contexto das práticas cênicas à distância. A qualificação da imagem sonora, ocorrida na passagem do teatrofone ao radioteatro, e a visualidade aportada pela imagem eletrônica no teleteatro indicam um crescente refinamento técnico-estético no interesse da imediação, ou seja, de condições capazes de operacionalizar uma mediação transparente de forma a provocar no espectador o sentimento de contato direto com a cena.

A tecnologia digital, o desenvolvimento acelerado de plataformas e aplicativos, passou a oferecer nos últimos anos inúmeras ferramentas, permitindo o surgimento tanto de criações pautadas pelo princípio da imediação, visando a imersão sensorial quanto de experimentos investidos na visibilidade dos meios. De um lado, há a simulação de ambientes, cuja experiência imersiva e vivência multissensorial estão diretamente relacionadas à qualidade da imediação do meio, ou seja, a sua transparência e a organização dos elementos sob o princípio da conjunção. Foi no fim dos anos de 1990 que começaram as primeiras experiências na rede de computadores de um teatro em ambientes virtuais 3D, por meio de programação em VRML. Destaca-se aqui o pioneirismo da adaptação de Sonho de uma noite de verão, concebida em VRML por Stephan Matsuba e Bernie Roehl ${ }^{8}$.

${ }^{8}$ Descrição do projeto VRML Dream. Disponível em:

https://ece.uwaterloo.ca/ smatsuba/about/vrmldream.html. Acesso em: 17 mai. 2021. 
Nessa experiência, tão solitária quanto aquela do teatrofone, o espectador passava a ter a possibilidade de escolher o ponto de vista no cenário virtual, podendo tanto se colocar diante da cena quanto visualizar a cena na perspectiva de um determinado personagem; essa autonomia de visualização colaborava para o fortalecimento do sentimento imersivo no ambiente virtual. Diferentemente das produções em chats, nessas criações os espectadores não têm sua presença marcada e, portanto, suas reações não podem ser identificadas, aspecto que compromete o despertar de um sentimento de coletividade ao qual nos referimos anteriormente.

De outro lado, criações em ambiente virtual investem na diversidade de ferramentas da tecnologia digital para compor uma escrita multimídia, incorporando textos, sobrepondo imagens, sequências sonoras e visuais e articulando possibilidades diversas de interação. Criações, portanto, investidas da hipermediação e organizadas segundo princípios da justaposição e da parataxe. Os elementos organizados de forma não inequívoca atribuem a essa telecena digital um potencial performativo. O mundo da tela, tradicionalmente associado à composição ilusionista, mostra-se então capaz de construir dissensos, rupturas e lacunas. Em criações como Carcaça e A Arte de Encarar o Medo, acima referidas, as interfaces encontram-se expostas, o contorno das janelas do Zoom aparecem separando aqueles que, poeticamente, estão juntos. A sobreposição da performance ao vivo com imagens pré-gravadas, como se vê em Carcaça, problematiza a experiência temporal do espectador e faz lembrar a afirmativa de Steve Dixon (2007, p.524):

a justaposição de temporalidades diferentes 'simultâneas' (ao vivo ou gravado/renderizados) problematiza a percepção do tempo e do espaço pelo espectador, a tal ponto que ao invés de suspender a descrença e experimentar o tempo da performance de acordo com os protocolos tradicionais de passividade do teatro ao vivo, uma percepção diferente de extratemporalidade é experienciada"

9 ..the juxtaposition of different "simultaneous" temporalities (live and record/computer rendered) can complicate the audience's perceptions of time and space to the extent that rather than simply "suspending disbelief" and experiencing performance time according to traditional passive protocols of live theater, a different perception of extratemporality is experienced. (Tradução nossa) 
A perspectiva do pós-pandemia suscita não só perguntas sobre o futuro do teatro, tal qual o conhecemos desde os gregos, mas também sobre o futuro do atual e intenso movimento de produções teatrais performativas na rede de computadores. A história é tranquilizadora. Sob ventos e tempestades, o teatro existe há bem mais do que dois mil anos. Ele sempre soube fazer de sua natureza efêmera a potência para uma existência eterna. As experiências pandêmicas poderão estimular o desenvolvimento mais amplo de performances de realidade mista, criações fundadas na articulação do ambiente real com o virtual, como aquelas realizadas pelo coletivo belga Crew, entre as quais, Terra Nova e Hamlet's Lunacy, ou como as ciberformances concebidas por Helen Jamieson.

Quanto às produções na rede de computadores, essas também não parecem fadadas a terminar, como ocorreu com outras telecenas. Elas devem sofrer mudanças de configuração, porque a tecnologia sofre avanços constantes. A chance de elas terminarem parece muito remota, pois constituem o sintoma de uma mudança psicossocial e cultural ampla, na qual a tecnologia vem promovendo novas formas de se estabelecer relações com a realidade. Parecem cada vez mais verdadeiros os entendimentos de Marshall McLuhan sobre a influência dos dispositivos técnicos sobre o pensamento humano e sua percepção da realidade. Se os meios tradicionais (imprensa, radio, televisão) aportaram efeitos sobre a apreensão humana da realidade, certamente, as tecnologias digitais foram provocadoras de mutações ainda mais significativas. Multiplicando as possibilidades de sua presença, ampliando a extensão de seu corpo por meio de próteses tecnológicas cada vez mais sofisticadas, vive-se hoje no entrelaçamento do real e do virtual. Essa vivência modifica as percepções de tempo e espaço, condição de toda experiência, por uma temporalidade marcada pela sincronização e pelo imediatismo dos atos de comunicação e por uma espacialidade fluida e ilimitada de uma navegação desordenada por meio de hiperlinks e o acesso a lugares até então inacessíveis. A aculturação pelas novas tecnologias, a experiência diária da interconectividade por elas promovidas fazem do ser humano contemporâneo um "homem digital", como antevia Negroponte (1995), e é por esses homens e mulheres que o teatro será concebido e para quem ele será realizado. 


\section{Referências}

ANDRADE, Carlos Drummond. José. São Paulo: Companhia das Letras, 2012.

BARDIOT, Clarisse. Les théâtres virtuels. Tese (Doutorado em Teatro), Université de Paris III, Paris, 2005.

BOLTER Jay; GRUSIN, Richard. Remediation: Understanding New Media. Boston: MIT Press, 1999.

CRAW, Victoria. Oxford University, AstraZeneca coronavirus vaccine: How preparation for 'Disease X' led to head start. Nationwide News Pty Limited, 24 nov. 2020. Disponível em: https://www.news.com.au/lifestyle/health/healthproblems/oxford-university-astrazeneca-coronavirus-vaccine-how-preparationfor-disease-x-led-to-head-start/news-story/a6a2a91b81ef54c861308d1e52755a6c. Acesso em: 08 fev. 2021.

DEEMER, Charles. The Deal: A Hyperdrama Demo. Theatre Network Magazine, Universitat di Valência, 18 jun. 2001. Disponível em: https://www.uv.es/ fores/programa/deemer hyperdrama2.html. Acesso em: 23 mar. 2021.

DIXON, Steve. Digital Performance. A History of New Media in Theater, Dance, Performance Art, and Installation. Cambridge: MIT Press, 2007.

DUBATTI, Jorge. Filosofia del Teatro 1: Convivio, Experiencia, Subjectividad. Buenos Aires: Atual, 2007.

GROTOWSKI, Jerzy. Em Busca de um Teatro Pobre. Rio de Janeiro: Civilização Brasileira, 1976.

HARRIS, Stuart. Virtual reality drama. Cyberlife. Indianópolis: Sam, p.497-520,1995.

JAMIESON, Helen Varley. Adventures in Cyberformance: Experiments at the interface of theatre and the internet. Dissertação (Mestrado em Arte), Queensland University of Technology, Queensland, Austrália. 2008. Disponível em: https://eprints.qut.edu.au/28544/1/Helen_Jamieson_Thesis.pdf Acesso em: 24 fev. 2021.

LAFARGE, Antoinette. A World Exhilarating and Wrong: Theatrical Improvisation on the Internet. Leonardo, the Journal of the International Society for the Arts, Sciences, and Technology, vol. 28, n. 5. 1995. Disponível em: https://www.jstor.org/stable/1576227?seq=1. Acesso em: 05 mar. 2021.

LEHMANN, Hans-Thies. Le Théâtre Postdramatique. Paris: Arche, 2002. 
MCLUHAN, Marshall. Os meios de comunicação como extensões do homem. São Paulo: Cultrix, 1969.

NEGROPONTE, Nicholas. A vida digital. São Paulo: Companhia das Letras, 2020. O DILEMA das redes sociais. Direção: Orlowski Jeff. Los Gatos, CA: Netflix, 2020. 1 vídeo (94 min). Documentário.

THOMAS, Tonia; COLIN-JONES Rachel. Voici comment le vaccin OxfordAstraZeneca été développé en un temps record. Le Journal du Dimanche, 20 jan. 2021. Disponível em: https://www.lejdd.fr/Societe/comment-le-vaccin-oxfordastrazeneca-a-ete-developpe-en-un-temps-record-4019695. Acesso em: 08 fev. 2021.

Recebido em: 01/05/2021

Aprovado em: 28/08/2021 